\title{
INOCULAÇÃO ARTIFICIAL DE COLMOS DE MILHO EM DIFERENTES IDADES E CONCENTRAÇÕES DE INÓCULO E SUA RELAÇÃO COM A EXPRESSÃO DA RESISTÊNCIA A Fusarium moniliforme $e^{*}$
}

\author{
MIRIAN F. BORGES**1, MÁRIO LÚCIO V. RESENDE***1 \& RENZO G. VON PINHO²
}

\author{
${ }^{1}$ Departamento de Fitopatologia; ${ }^{2}$ Departamento de Agricultura, Universidade Federal de Lavras, Cx. Postal 37, \\ CEP 37200-000, Lavras, MG, fax: (035) 829-1283, e-mail: mlucio@ufla.br
}

(Aceito para publicação em 09/05/2001)

Autor para correspondência: Mário Lúcio V. Resende

BORGES, M.F., RESENDE, M.L.V. \& VON PINHO, R.G. Inoculação artificial de colmos de milho em diferentes idades e concentrações de inóculo e sua relação com a expressão da resistência a Fusarium moniliforme. Fitopatologia Brasileira 26:715-720. 2001.

\section{RESUMO}

A podridão do colmo de milho (Zea mays) causada por Fusarium moniliforme tem ocorrência generalizada nas regiões produtoras do Brasil. Visando obter informações sobre o comportamento da doença, foram conduzidos dois experimentos em campo, um inoculando-se artificialmente colmo de plantas aos 30,55 e 80 dias após a semeadura, e outro testando-se diferentes concentrações de inóculo, $1 \times 10^{4}$, $5 \times 10^{5}$ e $1 \times 10^{7}$ conídios $/ \mathrm{ml}$, aplicadas aos 55 dias após a semeadura. Nesses experimentos utilizou-se o delineamento de blocos ao acaso, com respectivamente, quatro e cinco repetições, sendo cada parcela constituída de 50 plantas. As inoculações foram feitas no centro do segundo entrenó alongado acima do solo. A avaliação da doença foi realizada aos 120 dias após a semeadura, com base na sintomatologia interna do colmo, utilizando uma escala de notas variando de 1 a 9. Por ocasião da colheita foram avaliados o número de plantas acamadas e a produção de grãos. Procedeu-se também a análise do teor de lignina e tanino da casca e da parte interna do entrenó inoculado nos diferentes tratamentos. Todas as concentrações de inóculo testadas permitiram diferenciar os níveis de resistência dos híbridos, sendo estes decrescentes a partir do Cargill 333 para o Cargill 901, tendo o Dina 766 um comportamento intermediário. Por outro lado, não houve diferenças significativas para as inoculações em diferentes épocas. Os teores de taninos não foram significativamente diferentes entre os híbridos, já o teor de lignina foi significativamente relacionado com o nível de resistência dos três híbridos avaliados.

Palavras-chave adicionais: Doença fúngica, podridão do colmo, patogênese, mecanismos de resistência.

\section{ABSTRACT \\ Time of inoculation and inoculum concentration in relation to the expression of corn stalk resistance to Fusarium moniliforme}

Stalk rot is of generalized occurrence in the major maize (Zea mays) growing regions of the country. Seeking to evaluate the effects of inoculum concentration and plant age on the reaction of maize to Fusarium moniliforme, the stalks of three maize hybrids were artificially inoculated at the ages of 30, 55 and 80 days after planting using the inoculum concentrations of $1 \times 10^{4}$, $5 \times 10^{5}$ and $1 \times 10^{7}$ conidia $/ \mathrm{ml}$. Completely randomized block designs, respectively, with four and five replications were utilised in these experiments, being each plot constituted of fifty plants. The inoculations were carried out at the center of the second internode extended above soil level. Disease assessement was conducted 120 days post-planting, by using a score scale ranging from 1 to 9 , based on the internal necrosis of the stalk. By harvest time, the number of fallen plants and the grain yield were evaluated. The lignin and tanin contents of the rind, and of the internal part of the inoculated internode were also analyzed for different treatments. A significant difference among hybrids in their levels of resistance to $F$ moniliforme was observed, regardless of the inoculum concentration used and age of inoculation. On the other hand, there were no significant differences in disease levels obtained when stem inoculations with $F$. moniliforme were performed at different plants ages. Tanin contents were not significantly different among the hybrids, whereas lignin content was significantly related to the level of resistance of the three hybrids evaluated.

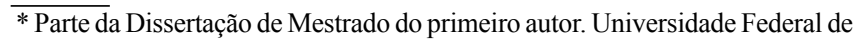
Lavras. (1999).

** Endereço atual: Univ. Federal de Viçosa, Departamento de Fitopatologia, CEP 36571-000, Viçosa, MG; e-mail: mfborges@alunos.ufv.br .

*** Bolsista de produtividade do CNPq.
}

\section{INTRODUÇÃO}

A ocorrência da podridão do colmo de milho (Zea mays L.) tem aumentado muito nos últimos anos nas principais regiões produtoras de milho do país. Vários patógenos podem 
estar associados a esta doença, sendo que o mais freqüente é o fungo Fusarium moniliforme Sheld. e sua forma perfeita Gibberella fujikuroi (Saw.) Wr. [sin. Gibberella moniliforme (Sheld.) Snyd.] (Nelson, 1992; Munkvold \& Desjardins, 1997).

A melhor forma de controle da doença é o uso de cultivares resistentes. No melhoramento genético sabe-se que a resistência de um híbrido à podridão do colmo é proporcional ao número de linhagens resistentes que entram em sua síntese. É de grande importância que as técnicas usadas para a avaliação e seleção de linhagens estejam bem definidas, sendo capazes de detectar fontes de resistência (Kappelman \& Thompson, 1966; Djordjevic \& Ivanovic, 1996).

A inoculação para avaliação da podridão do colmo passou a ser amplamente utilizada em programas de melhoramento de milho (Hooker, 1957), principalmente no estudo da herança da resistência (BeMiller \& Pappelis, 1965; Kappelman \& Thompson, 1966; Pappelis, 1970; Martin \& Russell, 1984a; Martin \& Russell, 1984b; Kang et al., 1986; Munkvold \& Carlton, 1997). Existe uma correlação positiva entre os dados obti $\lceil$ dos pela inoculação de colmos de milho e os obtidos pela infecção natural dos mesmos (Pappelis, 1970).

Alguns estudos procuraram determinar a melhor época para avaliação dos sintomas, com base na descoloração interna dos tecidos do colmo. Avaliações antes da quarta semana após a inoculação, podem conduzir à detecção de falsa resistência à $F$. moniliforme; assim, é preciso dar tempo para que a colonização do colmo alcance determinado grau, a partir do qual os aumentos de sintomas passem a ocorrer de maneira mais lenta (Hooker, 1957; Fernandes, 1975).

A maioria dos trabalhos encontrados na literatura procura verificar o efeito de inoculações no colmo feitas pouco antes ou durante o período reprodutivo das plantas. Deste modo, são escassas as informações sobre o desenvolvimento da doença quando as inoculações de $F$. moniliforme são feitas em plantas jovens de milho.

Segundo Koehler, (1960), citado por Fernandes (1975) a concentração de inóculo é também um importante fator na determinação da severidade dos sintomas em colmo de milho. Porém, não foi encontrado nenhum trabalho que determinasse uma concentração ideal para detectar resistência à $F$. moniliforme. Em geral utiliza-se concentrações com $1 \times 10^{6}$ ou $1 \times 10^{7}$ conídios/ml (Drepper \& Renfro, 1990; Munkvold et al., 1997).

Com relação aos mecanismos de resistência, verificase que tecidos do colmo com células em intenso metabolismo inibem a colonização por $F$. moniliforme. Isto está relacionado, entre outros fatores, com os teores de açúcares, sólidos solúveis, nitrogênio e substâncias fungistáticas (BeMiller \& Pappelis, 1964), teores estes que decrescem à medida que aumenta a senescência das plantas, aumentando, como conseqüência a suscetibilidade a $F$. moniliforme (Pinto et al., 1997). Uma maior predisposição da planta às infecções no colmo ocorre quando estas se encontram sob condições de estresse, como deficiência hídrica, excesso de nitrogênio em relação ao potássio (Foley \& Wernham, 1957) e alta incidência de manchas foliares. Com isso, inicia-se uma rápida e prematura senescência dos tecidos do colmo e em conseqüência uma maior suscetibilidade ao ataque de fungos causadores de podridões do colmo (Deacon, 1997).

Johann \& Dickson (1945), Whitney (1962), citados por Fernandes (1975), verificaram em testes com meios de cultura, a existência de uma correlação entre a composição química de extratos do colmo de plantas de milho e a resistência a F. moniliforme e Diplodia maydis (Berk) Sacc.. Os autores observaram que extratos de colmo obtidos antes ou pouco após a polinização apresentavam um efeito fungistático sobre os patógenos, indicando que o mecanismo de resistência à colonização era o mesmo para os dois fungos. Porém, inoculações com esses dois fungos juntos e individualmente, nas mesmas cultivares, mostraram que é possível detectar plantas resistentes a $F$. moniliforme, mas suscetíveis a $D$. maydis, provavelmente devido a uma maior virulência desse último (Fernandes, 1975).

A correta detecção de fontes de resistência no melhoramento genético depende do uso de metodologias de avaliação e seleção confiáveis. Assim, o objetivo do presente trabalho foi estudar os efeitos da inoculação artificial de $F$. moniliforme em diferentes idades de plantas de milho e com diferentes concentrações de inóculo. Procurou-se também quantificar os teores de tanino e lignina no colmo das plantas e verificar sua relação com o nível de resistência dos híbridos utilizados.

\section{MATERIAL E MÉTODOS}

Dois experimentos foram conduzidos em área experimental da Universidade Federal de Lavras, em Lavras, MG, para a avaliação da inoculação de colmos de híbridos de milho, respectivamente, em diferentes idades das plantas e com diferentes concentrações de inóculo de F. moniliforme.

\section{Produção de inóculo e inoculações}

As suspensões de conídios usadas para inoculações nos experimentos de campo, foram preparadas a partir de culturas com cinco dias de incubação em BDA. As concentrações desejadas foram determinadas com o auxílio de um hemacitômetro. Efetuaram-se testes de germinação com alíquotas dessas suspensões.

As inoculações foram realizadas através de uma punção em cada colmo, utilizando-se seringas descartáveis de $10 \mathrm{ml}$. Injetou-se um volume de $1,0 \mathrm{ml}$ da suspensão de conídios no centro do segundo internódio acima do solo (Munkvold \& Carlton, 1997).

\section{Experimento 1 - Reação de híbridos de milho à inoculação do colmo com $F$. moniliforme realizada em diferentes épocas}

Foram utilizados dois híbridos simples de milho, provenientes da empresa Cargill Agrícola S.A., o C333 (considerado resistente à podridão do colmo) e o C901 (considerado suscetível). Os colmos foram inoculados com 
Inoculação artificial de colmos de milho em diferentes idades e concentrações...

suspensão de conídios de $F$. moniliforme em diferentes idades: 30, 55 e 80 dias após a semeadura. Para cada híbrido foram utilizadas duas testemunhas: uma onde foi feita injeção de água destilada esterilizada e outra sem ferimento. Os tratamentos foram dispostos num delineamento de blocos ao acaso com quatro repetições em esquema fatorial 5 (épocas + testemunhas) x 2 (híbridos). Cada parcela foi constituída de duas fileiras de $5 \mathrm{~m}$ de comprimento e espaçadas de $0,8 \mathrm{~m}$, com cinco plantas $/ \mathrm{m}$. Os tratos culturais foram os comumente recomendados para a cultura. Foram inoculadas 50 plantas/ parcela, utilizando-se a concentração de $1 \times 10^{7}$ conídios $/ \mathrm{ml}$ (Munkvold \& Carlton, 1997).

Experimento 2 - Reação de híbridos de milho à inoculação artificial do colmo com diferentes concentrações de $F$. moniliforme

Foram avaliados três híbridos simples, sendo "C333" e "Dina766" considerados como resistentes à podridão por Fusarium e "C901" como suscetível. Nesse experimento foram utilizadas também duas testemunhas para cada híbrido, sendo uma mantida sem ferimento e na outra injetada água destilada esterilizada. Foram avaliadas três concentrações de inóculo: $1 \times 10^{4}, 5 \times 10^{5}$ e $1 \times 10^{7}$ conídios $/ \mathrm{ml}$. As inoculações foram realizadas aos 55 dias após a semeadura. Para esse experimento o delineamento empregado também foi o de blocos ao acaso com cinco repetições, em esquema fatorial 5 (concentrações de inóculo + testemunhas) x 3 (híbridos). Os detalhes das parcelas bem como de condução do experimento foram os mesmos relatados no experimento anterior.

\section{Avaliações}

Foi feita avaliação da severidade da podridão de colmo e determinada a produção de grãos. A severidade da podridão de colmo foi avaliada 120 dias após a semeadura, onde de uma fileira de cada parcela foi removida e os colmos seccionados longitudinalmente, para avaliação dos sintomas internos. Utilizou-se a escala diagramática desenvolvida por Giglioti \& Canteri (1998), com notas de 1 a 9. Na fileira remanescente da parcela, foi quantificada a produção de grãos, cujo teor de umidade foi medido e posteriormente corrigido para $13 \%$.

\section{Reisolamento}

Para verificar se $F$. moniliforme foi o patógeno responsável pelas lesões, fez-se reisolamento a partir de colmos colhidos aleatoriamente em cada tratamento. Esse procedimento foi feito nos dois experimentos. Utilizaram-se os meios ágar-água (20 g de ágar/l de água) e BDA acrescido de thiabendazole a $0,1 \%$ (para permitir o crescimento de outros fungos associados à doença).

\section{Análise dos teores de tanino e lignina no colmo de milho}

Em todos os tratamentos, nos dois experimentos, foram colhidas amostras de colmos dos híbridos usados para análise dos teores de lignina e tanino presentes nos tecidos internos e nos tecidos externos.
Para determinação do teor de lignina seguiu-se a metodologia proposta por Silva (1981). A extração do tanino foi feita de acordo com a metodologia descrita por Swain et al (1959) a qual fundamenta-se na sua solubilização em metanol. No doseamento do tanino seguiu-se o método colorimétrico de Folin-Dennis (A.O.A.C., 1960).

\section{Análise dos Dados}

Para cada experimento foram realizadas análises de variância para os dados de produção de grãos e de severidade de podridão no colmo. A verificação da distribuição normal dos dados foi feita com o auxílio do programa SAS for Windows (SAS Institute, Cary, NC), sendo que os valores de severidade, foram transformados para $[\ln (x+1)]$. As médias, inclusive aquelas provenientes dos teores de tanino e lignina nos colmos, foram comparadas pelo teste de agrupamento de Scott-Knott, a 5\% de probabilidade, no programa SAEG (Euclides, 1983).

\section{RESULTADOS E DISCUSSÃO}

Experimento 1 - Reação de híbridos de milho à inoculação de $F$. moniliforme realizada em diferentes épocas

Quanto à severidade de podridão do colmo, houve diferenças significativas entre os dois híbridos e entre os tratamentos aplicados, não sendo significativa a interação tratamento $\mathrm{x}$ híbrido. Não houve diferença significativa para inoculação em diferentes épocas (Tabela 1), independentemente do nível de suscetibilidade dos híbridos usados.

De acordo com Fernandes (1975), a avaliação da severidade feita antes da quarta semana após a inoculação, pode conduzir a erros na detecção da resistência a $F$. moniliforme. $\mathrm{O}$ autor afirma que este período de tempo é necessário para que a colonização avance e atinja um determinado ponto, a partir do qual o aumento da severidade evolua de forma mais lenta. No presente trabalho, os colmos foram avaliados internamente 120 dias após a semeadura. As percentagens de área lesionada encontradas não permitiram diferenciar as

TABELA 1 - Médias não transformadas da severidade (\% de área lesionada) de podridão do colmo do milho (Zea mays), causada por Fusarium moniliforme, nos híbridos C333 e C901 em função da época de inoculação

\begin{tabular}{lcr}
\hline \multirow{2}{*}{ Tratamento } & \multicolumn{2}{c}{ Híbridos } \\
\cline { 2 - 3 } & $\mathbf{C 3 3 3}$ & $\mathbf{C 9 0 1}$ \\
\hline Inoculação aos 30 dias & 8,9 a A & 36,6 a B \\
Inoculação aos 55 dias & 6,0 a A & 36,1 a B \\
Inoculação aos 80 dias & 9,1 a A & 40,1 a B \\
Testemunha injetada com água & 2,4 b A & 11,2 b B \\
Testemunha sem ferimento & 0,9 c A & 5,0 c B \\
\hline
\end{tabular}

CV(\%) 13,9

* Médias seguidas pela mesma letra, minúsculas nas colunas e maiúsculas nas linhas, não diferem significativamente entre si pelo teste de agrupamento ScottKnott a 5\% de probabilidade. 
idades de inoculação, apesar de ter havido em todos os tratamentos, tempo necessário para ocorrer colonização por F. moniliforme. A realização de apenas uma avaliação no final do ciclo da cultura pode ter sido responsável por este resultado. Seriam necessários mais estudos, aliando-se várias épocas de avaliação, procurando acompanhar o desenvolvimento conjunto patógeno-hospedeiro.

Foi encontrada diferença significativa entre as testemunhas e também entre os tratamentos de inoculação. Na maioria das plantas da testemunha sem ferimento, o colmo mostrava-se sadio sem nenhuma descoloração. $\mathrm{O}$ pequeno número de contaminações observadas pode ser atribuído à infecção natural, possivelmente proveniente de sementes infetadas ou de injúrias no colmo causadas por insetos e tratos culturais, como a capina. A testemunha injetada com água diferiu significativamente da absoluta, mostrando que o ferimento permitiu a penetração e conseqüentemente a infecção por F. moniliforme.

As médias de severidade da doença nos dois híbridos mostraram a diferença do nível de suscetibilidade (Tabela 1). Em todos os tratamentos, o híbrido C333 apresentou menor severidade, diferenciando-se significativamente do "C901".

Com relação a produção de grãos não houve diferença significativa para nenhuma das fontes de variação.

Experimento 2 - Reação de híbridos de milho à inoculação do colmo com diferentes concentrações de $F$. moniliforme

Houve diferenças significativas para os efeitos de tratamentos, híbridos e interação tratamentos $\mathrm{x}$ híbridos. Todos os desdobramentos da interação tratamentos $\mathrm{x}$ híbridos também foram significativos a $1 \%$ de probabilidade. Isolandose os efeitos dos tratamentos dentro de cada híbrido foi verificado que, para o híbrido C333, houve diferença significativa na severidade da podridão do colmo nas diferentes concentrações de inóculo de $F$. moniliforme, o que não foi observado para o "Dina766" e "C901" (Tabela 2). Neste trabalho o "Dina766", considerado resistente, comportou-se como híbrido suscetível. A não diferenciação das médias dos tratamentos pode ter sido resultado da maior suscetibilidade dos

TABELA 2 - Médias não transformadas da severidade (\% de área lesionada) de podridão do colmo do milho (Zea mays), causada por Fusarium moniliforme, nos híbridos C333, Dina766 e C901 em função do tratamento aplicado

\begin{tabular}{lccc}
\hline \multirow{2}{*}{ Tratamento } & \multicolumn{3}{c}{ Híbridos } \\
\cline { 2 - 4 } & $\mathbf{C 3 3 3}$ & Dina766 & C901 \\
\hline Conc. de $1 \times 10^{4}$ conídios $/ \mathrm{ml}$ & $9,40 \mathrm{~b} \mathrm{~B} *$ & 42,29 a A & 51,58 a A \\
Conc. de $5 \times 10^{5}$ conídios $/ \mathrm{ml}$ & 26,23 a B & 48,26 a A & 58,72 a A \\
Conc. de $1 \times 10^{7}$ conídios $/ \mathrm{ml}$ & 28,35 a B & 61,07 a A & 65,13 a A \\
Test. inoculada com água & 3,59 c B & 14,60 b A & 11,74 b A \\
Test. absoluta & $1,50 \mathrm{~d} \mathrm{~B}$ & 1,15 c B & $4,69 \mathrm{c} \mathrm{A}$ \\
\hline CV $(\%) 11,74$ & \multicolumn{3}{|}{} \\
\hline
\end{tabular}

* Médias seguidas pela mesma letra, minúsculas nas colunas e maiúsculas nas linhas, não diferem significativamente entre si pelo teste de agrupamento ScottKnott a $5 \%$ de probabilidade. híbridos Dina766 e C901.

Com base nos sintomas obtidos nos tratamentos testemunhas, confirma-se mais uma vez, que o ferimento provocado pela injeção com água, possibilita o aumento da infecção por F. moniliforme. Para o híbrido C333 os resultados obtidos reafirmam sua maior resistência à doença, uma vez que, em todos os tratamentos, a severidade da doença foi sempre significativamente menor que a obtida nos outros híbridos (Tabela 2).

Os híbridos C333 e Dina766 diferiram significativamente de "C901" quanto a produção média de grãos (Tabela 3). Os dados, principalmente das testemunhas não inoculadas, não permitiram afirmações sobre a influência direta da podridão do colmo na produção de grãos. Porém, a menor produção de "C901" nos tratamentos inoculados com o fungo, sugere que para esse híbrido, possa ter ocorrido influência da doença na granação.

Tanino e lignina como possíveis mecanismos de resistência à podridão do colmo em milho

A análise de variância dos dados relativos aos teores de tanino nos entrenós inoculados, tanto interna como externamente, não detectou diferenças entre os híbridos, nos dois experimentos. Porém, o híbrido C333 mostrou reação localizada à $F$. moniliforme. Os tecidos dos entrenós inoculados exibiram uma coloração marrom-avermelhada mais clara, que não foi observada nas plantas sadias da testemunhas sem ferimento desse híbrido, nem nos colmos do "Dina766" e do "C901" (Figura 1). Segundo Fernandes (1975) são encontrados relatos na literatura sobre a ação fungistática de extratos de colmo de plantas resistentes à podridão. Possivelmente, outros compostos possam estar envolvidos nas reações apresentadas pelos tecidos internos do híbrido C333.

Os teores de lignina dos tecidos dos entrenós inoculados dos híbridos testados no experimento 1, diferiram significativamente, tanto nos tecidos internos quanto nos externos (Tabela 4). Essa diferença foi confirmada nas médias do teor de lignina nos tecidos do entrenó inoculado dos híbridos do experimento 2 (Tabela 4). Observando-se a severidade apresentada pelas testemunhas sem ferimento, dos diferentes híbridos, parece que o teor de lignina dos tecidos externos estaria influenciando indiretamente, conferindo maior resistência ao colmo, e conseqüentemente, dificultando a penetração do F. moniliforme. Considerando-se os resultados

TABELA 3 - Médias da produção de grãos (Kg/ha) dos híbridos C333, Dina766 e C901 no experimento 2

\begin{tabular}{cl}
\hline \hline Híbridos & Médias \\
\hline C333 & $4.520 \mathrm{a}^{*}$ \\
D766 & $4.300 \mathrm{a}$ \\
C901 & $3.971 \mathrm{~b}$ \\
\hline
\end{tabular}

$\mathrm{CV}(\%) 15,7$

* Médias seguidas pela mesma letra não diferem significativamente entre si pelo Teste Scott-Knott a 5\% de probabilidade. 
Inoculação artificial de colmos de milho em diferentes idades e concentrações...
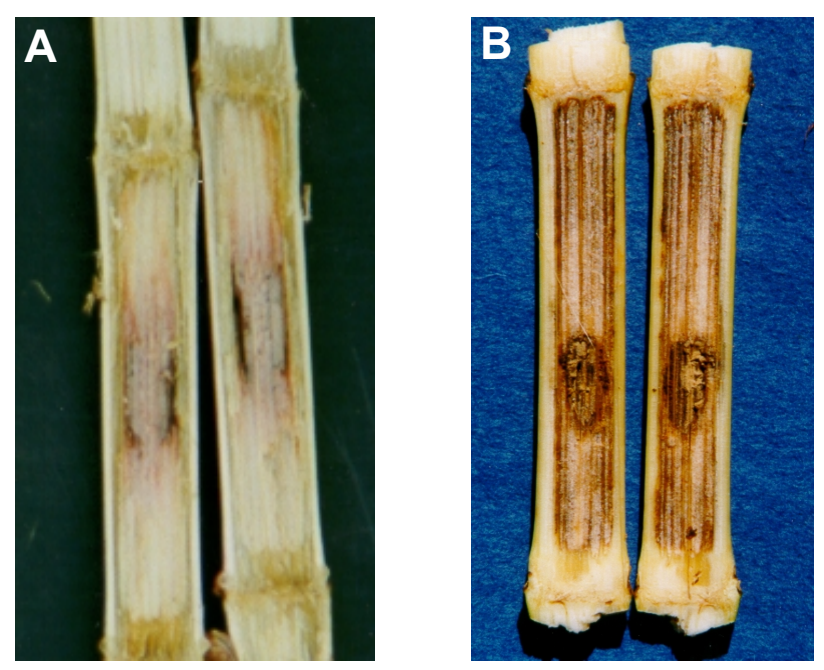

FIG. 1 - Reação dos tecidos internos do colmo do milho (Zea mays) dos híbridos C333 (A) e C901 (B) à colonização por Fusarium moniliforme inoculado artificialmente.

TABELA 4 - Médias do teor de lignina (\% na matéria seca) nos tecidos internos e externos do entrenó do colmo do milho (Zea mays) inoculado dos híbridos C333, Dina766 e C901 (experimento 1 e 2)

\begin{tabular}{lcccc}
\hline \hline \multirow{2}{*}{ Híbrido } & \multicolumn{2}{c}{ Experimento 1 } & \multicolumn{2}{c}{ Experimento 2 } \\
\cline { 2 - 5 } & $\begin{array}{c}\text { Tecidos } \\
\text { internos }\end{array}$ & $\begin{array}{c}\text { Tecidos } \\
\text { externos }\end{array}$ & $\begin{array}{c}\text { Tecidos } \\
\text { internos }\end{array}$ & $\begin{array}{c}\text { Tecidos } \\
\text { externos }\end{array}$ \\
\hline C333 & $7,14 \mathrm{a}^{*}$ & $15,24 \mathrm{a}$ & $7,17 \mathrm{a}$ & $14,88 \mathrm{a}$ \\
D766 & - & - & $6,68 \mathrm{a}$ & $14,74 \mathrm{a}$ \\
C901 & $6,32 \mathrm{~b}$ & $12,22 \mathrm{~b}$ & $5,76 \mathrm{~b}$ & $11,68 \mathrm{~b}$ \\
\hline
\end{tabular}

* Médias seguidas pela mesma letra nas colunas não diferem significativamente entre si pelo Teste Scott-Knott a 5\% de probabilidade.

de área lesionada nos híbridos testados, provavelmente o maior teor de lignina nos tecidos internos pode também estar contribuindo para um maior nível de resistência.

Considerando-se as condições em que foi desenvolvido o presente trabalho, verificou-se que a menor concentração de inóculo usada, $1 \times 10^{4}$ conídios de $F$. moniliforme por ml, permitiu a exteriorização do nível de suscetibilidade nos híbridos testados, e que a inoculação da planta com $F$. moniliforme acima dos 30 dias após plantio não influenciou significativamente a severidade de podridão do colmo no final do ciclo da cultura. Para um melhor esclarecimento do comportamento de $F$. moniliforme na colonização do colmo e sua interferência na produção, devem ser desenvolvidos estudos combinando diferentes épocas de inoculação e diferentes épocas de avaliação. Com relação aos teores de tanino parece não haver influência desse composto na resistência à podridão do colmo causada por $F$. moniliforme; já o nível de lignificação dos tecidos está provavelmente relacionado com resistência.

\section{REFERÊNCIAS BIBLIOGRÁFICAS}

A.O.A.C. Official Methods of Analysis of the A.O.A.C. $9^{\text {th }}$ ed., Washington, 1960.

BEMILLER, J.N., PAPPELIS, A.J. 2,4-Dihydroxy-7methoxy-1,4-benzoxazin-3-one glucoside in corn. I. relation of water-soluble, 1-butanol-soluble glycoside fraction content of pith cores and stalk rot resistance. Phytopathology 55:1237-1240. 1965.

BEMILLER, J.N., PAPPELIS, A.J. Relationship of glycoside content to corn stalk rot resistance. Phytopathology 54:888. 1964.

DEACON, J.W. Modern Mycology. ed. 3. Ed. Blackwell Science 1997.

JORDJEVIC, J.S. \& IVANOVIC, M.R. Genetic analysis for stalk lodging resistance in narrow-base maize synthetic population ZPS14. Crop Science 36:909-913. 1996.

DREPPER, W.J. \& RENFRO, B.L. Comparison of methods for inoculation of ears and stalks of maize with Fusarium moniliforme. Plant Disease 74:952-956. 1990.

EUCLIDES, R.F. Sistema para análises estatísticas e genéticas (SAEG). Central de Processamento de Dados. Viçosa: UFV, 1983.

FERNANDES, F.T. Avaliação de cultivares de milho (Zea mays L) quanto à suscetibilidade a Fusarium moniliforme e Diplodia maydis após inoculação artificial dos colmos. (Tese de Mestrado) Piracicaba, Escola Superior de Agricultura Luiz de Queiroz, 1975.

FOLEY, D.C. \& WERNHAM, C.C. The effect of fertilizers on stalk rot of corn in Pennsylvania. Phytopathology 47:11-12. 1957.

GIGLIOTI, E.A. \& CANTERI, M.G. Desenvolvimento de software e escala diagramática para seleção e treinamento de avaliadores da severidade do colmo do complexo broca-podridões em cana-de-açúcar. Fitopatologia Brasileira 23:359-363. 1998.

HOOKER, A.L. Factors affecting the spread of D. zeae in inoculated corn stalks. Phytopathology 47:196-199. 1957.

KANG, M.S., PAPPELIS, A.J. \& ZUBER, M.S. Effect of stalk inoculation (Diplodia maydis) on parenchyma cell death in cob and stalk internodes of maize. Cereal Research Communications 14:267-272. 1986.

KAPPELMAN, A.J. \& THOMPSON, D.L. Inheritance of resistance to Diplodia stalk-rot in corn. Crop Science 6:288-290. 1966.

MARTIN, M.J. \& RUSSELL, W.A. Correlated responses of yield and other agronomic traits to recurrent selection for stalk quality in a maize synthetic. Crop Science. 24:746-750. 1984a.

MARTIN, M.J. \& RUSSELL, W.A. Response of a maize synthetic to recurrent selection for stalk quality. Crop Science 24:331-337. 1984b.

MUNKVOLD, G.P. \& CARLTON, W.M. Influence of inoculation method on systemic Fusarium moniliforme infection of maize plants grown from infected seeds. 
Plant Disease 81:211-216. 1997.

MUNKVOLD, G.P. \& DESJARDINS, A.E. Fumonisins in Maize. Can we reduce their occurrence? Plant Disease 81:556-565. 1997.

MUNKVOLD, G.P., McGEE, D.C. \& CARLTON, W.M. Importance of different pathways for maize kernel infection by Fusarium moniliforme. Phytopathology 87:209-217. 1997.

NELSON, P.E. Taxonomy and biology of Fusarium moniliforme. Mycopathologia 17:29-36. 1992.

PAPPELIS, A.J. Effect of root and leaf injury on cell death and stalk rot susceptibility in corn. Phytopathology 60:355-357. 1970.

PINTO, N.F.J.A., FERNANDES, F.T. \& OLIVEIRA, E. Milho (Zea mays) Controle de doenças. In: Vale, F.C.R. do \& Zambolim, L. (Eds.) Controle de doenças de plantas: grandes culturas. Viçosa - MG:UFV, Dep. de Fitopatologia; Brasília - DF: Ministério da Agricultura e do Abastecimento. 1997. pp. 821-857.

SILVA, D.J. da. Análise de alimentos (métodos químicos e biológicos). Viçosa, Universidade Federal de Viçosa, Impressa Universitária, 1981. 